\title{
Research trends on argumentation in science education: a journal content analysis from 1998-2014
}

\author{
Sibel Erduran ${ }^{1 *}$, Yasemin Ozdem² and Jee-Young Park ${ }^{3}$
}

\begin{abstract}
Background: The primary objective of this paper is to provide a review of research on argumentation in science education based on publications from 1998 to 2014 in three science education journals. In recent years, the teaching and learning argumentation (i.e. the coordination of evidence and theory to support or refute an explanatory conclusion, model or prediction) has emerged as a significant educational goal. Argumentation is a critically important discourse process in science and it should be taught and learned in the science classroom as part of scientific inquiry and literacy. Argumentation stresses the evidence-based justification of knowledge claims, and it underpins reasoning across STEM domains. Our aim in this study was to investigate how argumentation has been positioned within the publications of three top academic journals: Science Education, International Journal of Science Education, and Journal of Research in Science Teaching. A methodology for content analysis of the journals is described using quantitative and qualitative techniques.

Results: One of the contributions of our analysis is the illustration that researchers studying argumentation from a linguistic perspective have been emphasizing related concepts in different ways. While the emphasis has been on discourse and discussion across all journals, the related concepts of talk, conversation, dialogue and negotiation were observed to a lesser extent. Likewise, the fine-level analysis of the key epistemic concepts such as reasoning, evidence and inquiry indicates variation in coverage.

Conclusions: The findings can provide evidence-based indicators for where more emphasis needs to be placed in future research on argumentation, and in particular they can provide guidelines for journals in soliciting articles that target underemphasized aspects of argumentation in science education.
\end{abstract}

Keywords: Argumentation; Journal content analysis; Trends in research; Science education

\section{Background}

The primary objective of this paper is to provide a review of argumentation studies in science education in manuscripts published from 1998 to 2014 in key science education research journals. In recent years, the teaching and learning argumentation (i.e. the coordination of evidence and theory to support or refute an explanatory conclusion, model or prediction) has emerged as a significant educational goal. Argumentation is a critically important discourse process in science and it should be taught and learned in the science classroom as part of scientific

\footnotetext{
* Correspondence: sibel.erduran@ul.ie

'University of Limerick, Castletroy, Co., Limerick, Ireland

Full list of author information is available at the end of the article
}

inquiry and literacy (Erduran \& Jimenez-Aleixandre 2012; Erduran \& Jimenez-Aleixandre 2007; JimenezAleixandre et al. 2000; Kelly \& Takao 2002; Zohar \& Nemet 2002). Argumentation stresses the evidence-based justification of knowledge claims, and it underpins reasoning across STEM domains. Our aim in this study was to investigate how argumentation has been positioned within the publications of top academic journals: Science Education (SE), International Journal of Science Education (IJSE) and Journal of Research in Science Teaching (JRST). Our selection of these journals is consistent with other recent studies that have concentrated on journal content analysis in science education (e.g. Chang et al. 2010; Lee et al. 2009). 
Content analysis of academic journals is an important aspect of educational research (Bowen 1992; Chang et al. 2010; Henson 2001). There are high-impact journals such as the Review of Educational Research ranked first in the Thompson Reuters Citation Reports that are dedicated to the analysis of research literature. Content analysis of journals provides researchers with insight into recent and emerging trends of key themes in the literature (e.g. Chang et al. 2010; Lee et al. 2009; Lin et al. 2014). Another significant aspect of journal content analysis is that it can provide evidence-based indicators for where more emphasis needs to be placed in research in order to understand how to improve the educational sector (Foreman-Peck \& Winch 2010). In short, content analysis of journals can be useful in conceptualizing recent trends (e.g. Lee et al. 2009), forging new levels of interpretation of the literature (e.g. Anderson et al. 2006) and providing synthesis of ideas (e.g. Slavin et al. 2009).

Our focus in this review was on argumentation in science education. Argumentation was identified as an area of research in science education that has gained significant attention in recent years (Lee et al. 2009). Attention given to argumentation is apparent in the recent review by Lin et al. (2014) showing that the top 10 highly cited papers in 1998-2002 included papers on argumentation. The review also illustrated that a handful of the top 10 highly cited papers in 2003-2007 were concerned with argumentation, including those with a focus on informal reasoning (Lin et al. 2014). It was also reported that argumentation is in the list of the top 10 highly cited papers in 2008-2012, along with inquiry and scientific modelling. These review data support the claim that the argumentation was a significant topic of investigation and has received enduring attention from science educators for over a decade (Lee et al. 2009; Lin et al. 2014). Despite the increasing interest in argumentation in science education research, the precise nature of the trends in its coverage has not been previously documented in detail. Therefore, this study aimed to contribute to the understanding of the trends in the research literature through a content analysis of some key journals in the field.

Lin et al. (2014) indicated that in the past 15 years, argumentation, including informal reasoning, has been studied mostly in the context of various socio-scientific issues, suggesting that these three research topics were widely considered to be closely interrelated by science educators. Similarly, within science education, the notions of 'epistemic practices', and 'discourse' have been intricately linked to argumentation studies (Erduran \& Jimenez-Aleixandre 2007).

On the other hand, Buty and Plantin (2008) point out that the established community working on argumentation studies does not tend to take into account the contributions of science education. Evidence for this lack of attention can be found in reference books, in the scarce presence of science education-related papers in journals such as Argumentation. In this paper, therefore, we focus on the argumentation studies in top science education journals in order to contribute to the understanding of the development of argumentation theory in science education in relation to their foundational grounding particularly in relation to the epistemic and linguistic aspects.

\section{Theoretical framework}

Argumentation can be described as a kind of discourse through which knowledge claims are individually and collaboratively constructed and evaluated in the light of empirical or theoretical evidence (Erduran \& JimenezAleixandre 2007). As a relatively unfamiliar strategy, argumentation needs to be appropriated by children and explicitly taught through suitable instruction, task structuring and modelling (e.g. Mason 1996). The teaching and learning of argumentation are based on premises that are consistent with the wider literature in science education, namely in framing science learning in terms of the appropriation of community practices that provide the structure, motivation and modes of communication required to sustain scientific discourse (Kelly \& Chen 1999; Lemke 1990). From this perspective, argumentation is a significant tool that is instrumental in the growth of scientific knowledge (Kitcher 1988) as well as a vital component of scientific discourse (Pera 1994). The implication is that argumentation plays a central role in the building of explanations, models and theories (Siegel 1989) as scientists use arguments to relate the evidence they select to the claims they reach through use of warrants and backings (Toul$\min 1958)$.

International curriculum and policy documents have been advocating the incorporation of argumentation in science education. Within Europe, the distinctive feature of argumentation is that it is framed in the development of the scientific competence. Jiménez-Aleixandre and Federico-Agraso (2009) illustrate this point through a discussion of the European Union recommendation of eight key competences (European Union 2006). In other parts of the world, for instance in the USA, argumentation is framed in the context of scientific practices (Berland \& Reiser 2009). The recent development of the Next Generation Science Education Standards following on from the National Research Council's recommendations (National Research Council 2012) is testimony to the articulation of argumentation as a significant component of scientific practices. 
There are at least three theoretical bodies of research framing argumentation studies: (a) developmental psychology, including the distributed cognition perspective; (b) language sciences, for instance the theory of communicative action; and (c) science studies, for instance, drawing on history, philosophy and sociology of science. As Erduran \& Jimenez-Aleixandre (2007) argued, rather than being a one-way relationship, argumentation studies and science education have the potential to inform these perspectives, leading to fruitful interactions. Likewise, we contend that within science education, the study of how argumentation studies have been informed by foundational perspectives is important in setting the scene for potential reciprocal interdisciplinary investigations of argumentation (Erduran \& Jimenez-Aleixandre 2007) with contributions of science education research to other fields. For example, (a) the discussions about to what extent argumentation research in science education contributes to cognitive and metacognitive processes would inform the situated cognition perspective (Brown \& Campione 1990); (b) the development of communicative competences and particularly critical thinking by means of argumentative science education would add to the theory of communicative action; (Habermas 1981); and (c) understanding the development of reasoning through argumentation in science education could extend our knowledge about teaching and learning philosophy of science (Giere 1988) as well as developmental psychology (Kuhn \& Crowell 2011).

In this paper, we focus on the coverage of the epistemic and linguistic aspects of argumentation. Apart from the theoretical rationale as illustrated, reason for this choice is that argumentation is closely interrelated with these dimensions in international curriculum and assessment documents. For example, The PISA framework (Organisation for Economic Cooperation and Development 2006, p. 29) emphasizes three dimensions of the scientific competence characterized as the abilities to

- Identify scientific issues and questions that could lend themselves to answers based on scientific evidence.

- Explain or predict phenomena by applying appropriate knowledge of science.

- Use scientific evidence to draw and communicate conclusions and to identify the assumptions, evidence and reasoning behind conclusions.

Among these aims, it is the third that can be identified as targeting the same practices as argumentation, namely the use of evidence to evaluate scientific claims, be it to draw conclusions from evidence or to identify the evidence behind conclusions. Though, certainly, the three dimensions are related.
In the USA, National Research Council (2012), p.49) outlines the key aspects of scientific practices as follows:

1. Asking questions (for science) and defining problems (for engineering)

2. Developing and using models

3. Planning and carrying out investigations

4. Analysing and interpreting data

5. Using mathematics and computational thinking

6. Constructing explanations (for science) and designing solutions (for engineering)

7. Engaging in argument from evidence

8. Obtaining, evaluating and communicating information.

Argumentation is explicitly stated in Practice 7 ('Engaging in argument from evidence'), and it is also implicitly covered in Practices 4 ('Analyzing and interpreting data') and 8 ('Obtaining, evaluating and communicating information'). The general aims that integrate features of argumentation are focused on empowering students to talk and to write science as well as on supporting their enculturation into science communities and their acquisition of epistemic criteria for knowledge evaluation. These perspectives address the epistemic and linguistic aspects of argumentation.

Epistemic practices are the cognitive and discursive activities that are targeted in science education to develop epistemic understanding (e.g. Duschl 2008; Duschl \& Grandy 2008). These practices include the articulation and evaluation of knowledge, coordination of theory and evidence, making sense of patterns in data, and holding claims accountable to evidence and criteria all aspects of scientific argumentation. The argumentation studies addressing the understanding of scientific epistemology resulted in the observation that students have to be in instructional contexts where they make explicit epistemic decisions to understand scientific practices (Sandoval \& Millwood 2005). Sandoval and Millwood argued that to make the epistemic decisions explicit, pedagogical strategies such as constructing and evaluating arguments are needed. Similarly, Erduran \& Jimenez-Aleixandre (2007) claimed that argumentation, involving the justification of claims through evidence, may support the development of scientific epistemology and understanding of the practices of the scientific community. The role of language, particularly the relation between ways of thinking and talking, has been prevalent across many areas of science education (and not only in argumentation) due to prevalence of sociocultural theories of learning through the popularization of Lev Vygotsky's work (e.g. Lemke 1990; Mortimer \& Scott 2003).

In summary, our aim in this study was to investigate to what extent the argumentation research in science 
education utilized epistemic and linguistic perspectives in contribution to the development of argumentation theory in science education with the potential to influence the achievement of related goals in educational outcomes.

\section{Methods}

The methodological process followed the steps of review methods, which were developed by the Evidence for Policy and Practice Information and Coordinating Centre for systematic reviews of educational research literature (Bennett et al. 2005). The review has three main phases as follows:

1. Selection of research papers related to argumentation for analysis: The criteria by which studies are to be included in, or excluded from, the review were determined. The studies which appear to meet these criteria were listed by means of electronic database searching, and then the abstracts of the studies were screened to see if they meet the inclusion criteria.

The study is based on the review of published articles in the journals SE, IJSE and JRST from 1998 to 2014. The rationale for the choice of these three journals is that they are the major journals that have high impact factors in science education research. Book reviews, replies, erratum and editorial materials were all excluded because we were interested in investigating original research contributions. The number of total articles was 3,076 , of which approximately $5 \%$ were related to argumentation.

The research related to argumentation was sorted out through electronic database search, where the criterion was to include the keyword stem 'argu-' (to detect the words argue, arguing, argument, argumentation). A second-level screening of the abstracts resulted in the exclusion of some of the articles since the keyword 'argue' does not refer to the content of argumentation in science education but only is used as a verb in a generic sense, like 'as researcher, we argue that...' Once this step eliminated irrelevant articles, it was sufficient for an article to include just one of the keywords to be included in the analysis. The resulting number of research articles is provided in Table 1.

2 Identifying keywords and generating systematic categories: Each of the included studies was coded against a pre-agreed list of keywords related to epistemic and linguistic aspects of argumentation. The list was then used to generate a systematic map of the argumentation studies. The studies were grouped according to their emphasis on each of these aspects denoted by the keywords.
Table 1 The distribution of argumentation-related research articles across journals

\begin{tabular}{lllll}
\hline & SE & IJSE & JRST & Total \\
\hline Total number of articles & 703 & 1,539 & 834 & 3,076 \\
Articles including keyword argumentation & 27 & 50 & 27 & 104 \\
Articles including keyword argu- & 13 & 24 & 12 & 49 \\
Articles related to argumentation & 40 & 74 & 39 & 153 \\
& $5.7 \%$ & $4.8 \%$ & $4.7 \%$ & $5.0 \%$ \\
\hline
\end{tabular}

The researchers agreed on a list of keywords addressing epistemic, linguistic and wider epistemic aspects of argumentation. The keyword identification was based on the potential contributions from the introduction of argumentation in the science classrooms, drawn from diverse foundational disciplines such as philosophy, linguistics and communication (Erduran \& JimenezAleixandre 2007). For example, we identified the keywords 'claim,' 'evidence,' 'justif-' (to detect the words such as justification, justify, justifying) and 'reason-' (to detect the words such as reasoning, reason) in order to address argumentation-specific epistemic aspects. The linguistic aspects of argumentation were addressed by means of the keywords 'talk', 'discuss', 'discourse', 'conversation', 'dialog-' (to detect the words such as dialogue, dialogic, etc.) and 'negotiat-' (to detect the words such as negotiation, negotiate). These keywords were identified considering the relation of argumentation to the communicative competencies and socio-cultural perspectives. The keywords 'inquiry' and 'expla-' (to detect the words such as explain, explanation) address wider epistemic aspect of argumentation. We wanted to differentiate the argumentation-specific epistemic aspects such as 'reason' and 'justification' from broader epistemic aspects such as 'explanations' and 'inquiry' which can potentially be explored without a specific emphasis on argumentation. In the analyses of the data in this study, these two aspects (argumentation-specific epistemic and wider epistemic) were considered under the category of epistemic aspect of argumentation. Table 2 summarizes the keywords framing the categories.

An article may have had more than one occurrence of a keyword, but the category was coded just once to indicate that article includes that keyword. In other words, for the purposes of this analysis, we were not interested in the frequency but rather the occurrence of whichever aspect of argumentation. Moreover, the meaning of a keyword in a research article was taken into account since the keyword might not be used in relation to argumentation. For example, when inspecting the keyword 'discuss', if the researchers used it in a way to indicate their discussion related to the findings of the study such that 'The findings and further implications of the study were discussed' that article was not coded as having the 
Table 2 Contributions of argumentation, keyword identification and categories

\begin{tabular}{lll}
\hline Potential contributions of argumentation & The category/aspect of argumentation & The keywords addressing the aspect \\
\hline $\begin{array}{l}\text { The development of epistemic criteria for knowledge } \\
\text { construction, evaluation and reasoning }\end{array}$ & Argumentation-specific epistemic aspect & Claim, evidence, justif- and reason- \\
$\begin{array}{ll}\text { The enculturation into the practices of scientific culture } \\
\begin{array}{l}\text { The development of communicative competencies } \\
\text { and socio-cultural perspective }\end{array}\end{array}$ & $\begin{array}{l}\text { General/wider epistemic aspect } \\
\text { Linguistic aspect }\end{array}$ & $\begin{array}{l}\text { Inquiry and expla- } \\
\text { Talk, discuss, discourse, conversation, dialog- } \\
\text { and negotiat- }\end{array}$ \\
\hline
\end{tabular}

keyword 'discuss'. Instead, if the researchers used the keyword to indicate a communicative competency such as 'Students involved in small-group discussion', the article is considered to be one addressing a linguistic aspect of argumentation.

3. In-depth review and data extraction: The studies were listed and evaluated according to the categories described in 1 and 2 to identify the patterns such as the distribution of articles related to argumentation in all journals across time and across journal, and the distribution of articles based on epistemic and linguistic aspects.

\section{Results and discussion}

All of the published papers in SE, IJSE and JRST between the years 1998 and 2014 were analysed first for whether or not argumentation was covered and, second, for their emphasis on different aspects of argumentation. In total, among 3,076 articles during this period, approximately $5 \%$ of articles related to broad range of 'argumentation' research (Table 1). This ratio of articles related to argumentation within each journal is different for SE as the highest of all (5.7\%) and quite similar for IJSE and JRST (4.8\% and 4.7\%, respectively).

\section{Trends across years and across journals}

In order to identify chronological trends in the argumentation literature across the timeframe covered, we looked for the number of argumentation articles published each year in each of the journals (see Figure 1). The number of argumentation-related articles each year increased gradually. For example, between the years 1998 and 2002, there were 19 articles published; between 2003 and 2007, there were 27 articles; between years 2008 and 2012, there were 69 articles; and the last 2 years, the total number of argumentation-related articles was 38. The trend is that the number of articles published in the last 7-year period (2008-2014), which was 107 , is more than twice of the previous 7-year period (2001-2007), which was 36, and more than the total of the first 10-year period (1998-2007), which was 46. This trend indicates a steady increase in the amount of research reported on argumentation in the last 7 years.

The investigation of the distribution of articles for each journal across time provided a chronological pattern regarding to what extent a specific journal followed a similar tendency towards argumentation as the general pattern. The results showed that all three journals published research articles related to argumentation in increasing numbers across the timeframe investigated. The only exception for this trend is that in JRST, there was a slight decrease between 2003 and 2007.

The highest frequency of publication of argumentationrelated studies in a journal was seen between 2007 and 2014 for all three journals. In other words, IJSE published $78.4 \%$ of argumentation-related articles between these years, while JRST published $71.8 \%$ and SE published

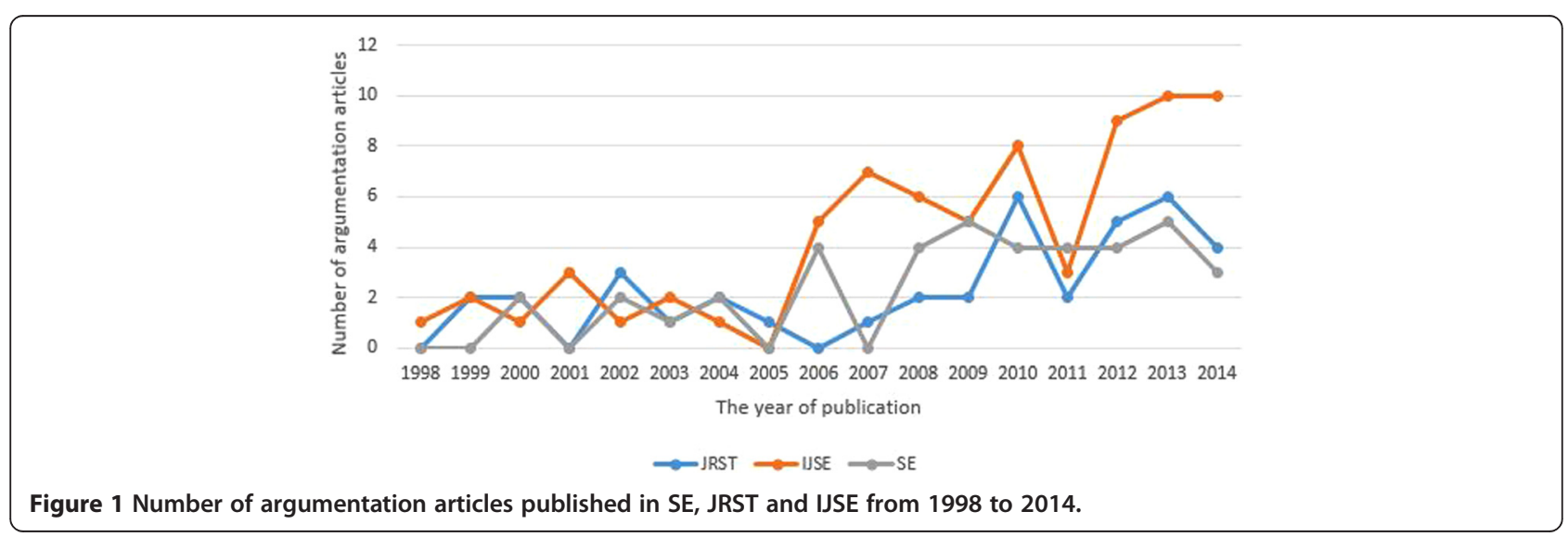


$72.5 \%$ in this period. However, in total, the highest frequency between 2007 and 2014 was in IJSE. That is, of the 115 argumentation-related articles in total in this period, $50.4 \%$ were published in IJSE, followed by $25.2 \%$ in SE and $24.4 \%$ in JRST.

\section{Trends related to epistemic and linguistics aspects}

Overall, there were 153 articles that used the term argumentation or argu- explicitly in the title or abstract. These articles were further examined against a preagreed list of keywords in terms of their emphasis on epistemic or linguistic aspects of argumentation. A high percentage of research articles (90.2\%) in all three journals considered argumentation from epistemic and/or linguistic perspective (Table 3 ).

The research articles in each journal put more emphasis on the epistemic aspects as compared to the linguistic aspects. For example, in SE and JRST, while there were 31 articles addressing epistemic aspects of argumentation, there were 27 articles addressing linguistic aspects. The difference between two aspects in IJSE was more pronounced. That is, there were 54 articles addressing epistemic aspects and 45 articles addressing linguistic aspects.

The distribution of epistemic and linguistic aspects for time periods across journals gave a picture of how the trends within argumentation research have evolved (Figure 2). We selected the first time period to be 19982006 because this time period represents the release of argumentation studies in three journals until there is a sharp increase in the number of studies as indicated above. After the year 2007, the time periods were divided into 2-year intervals to observe the trends more closely across the journals in terms of their emphasis on epistemic and linguistic aspects. In line with the increase of interest in argumentation research in science education beginning in 2007, the number of articles

Table 3 The number of argumentation articles addressing epistemic and/or linguistic aspects of argumentation

\begin{tabular}{lllll}
\hline Articles addressing & \multicolumn{5}{c}{ Number of articles } \\
\cline { 2 - 6 } & SE & IJSE & JRST & Total \\
\hline Articles related to argumentation & 40 & 74 & 39 & 153 \\
Linguistic aspects of argumentation & 31 & 54 & 31 & 116 \\
Epistemic aspects of argumentation & 27 & 45 & 27 & 99 \\
Both aspects of argumentation & 22 & 34 & 21 & 77 \\
None of the two aspects of argumentation & 4 & 9 & 2 & 15 \\
Only one aspect of argumentation & 14 & 31 & 16 & 61 \\
Only epistemic aspects of argumentation & 9 & 20 & 10 & 39 \\
Only linguistic aspect of argumentation & 5 & 11 & 6 & 22 \\
\hline
\end{tabular}

addressing epistemic aspects and linguistic aspect showed increase, too. However, it makes sense to evaluate the trend by looking at the percentage of articles addressing each aspect for each time period within the total number of articles published in that time period.

The research on argumentation puts heavy emphasis either on epistemic and/or linguistic aspects of argumentation or both aspects at the same time. The other aspects of argumentation have been investigated in relatively low percentages in each time period ( $8 \%$ between 1998 and 2006, 10\% between 2007-2008 and 20092010, 7\%\% between 2011 and 2012 and 13\% between 2013 and 2014). The epistemic aspects of argumentation received much more attention by researchers through almost all time periods, with an exception of 2007-2008 timeframe. However, it is plausible that researchers tended to consider these two aspects to be highly interrelated. Indeed, considering the intertwined perspectives in argumentation research in science education, it makes sense that these two aspects were examined together in high percentages in each time period and retained their importance since 1998 at almost the same rate $(55 \%$ between 1998 and 2006, 50\% between 2007 and 2008, 57\% between 2009 and 2010, 44\% between 2011 and 2012 and 45\% between 2013 and 2014).

When each journal was investigated separately, some fluctuations in the patterns were observed. For example, according to the graph demonstrating the articles addressing epistemic aspects for each journal (Figure 3), the frequency was lower in the last years compared to the early years of argumentation research in science education for IJSE (from 81.7\% between 1998 and 2006 to $70 \%$ between 2013 and 2014) whereas in JRST and SE, there were fluctuations in the trends across the years eventually leading to more argumentation studies focusing on epistemic aspects in JRST (from 81.8\% between 1998 and 2006 to $75 \%$ between 2009 and 2010 and to 90\% between 2013 and 2014), but less attention to this aspect in SE (from 63.6\% between 1998 and 2006 to $88.9 \%$ between 2009 and 2010 and to $75 \%$ between 2013 and 2014).

The trend in research addressing linguistic aspects for each journal across time was similar (Figure 4). In particular, in two journals, SE and IJSE, the interest in linguistic aspects dropped, compared to the early years (from 81.8\% between 1998 and 2006 to 50\% between 2013 and 2014 for SE and from 68.8\% between 1998 and 2006 to $50 \%$ between 2013 and 2014 for IJSE). However, in JRST, papers reported on the linguistic aspects in gradually increasing percentages (from 63.6\% between 1998 and 2006 to $70 \%$ between 2013 and 2014).

We should note that the research articles addressing the linguistic aspects along with the epistemic aspects or 


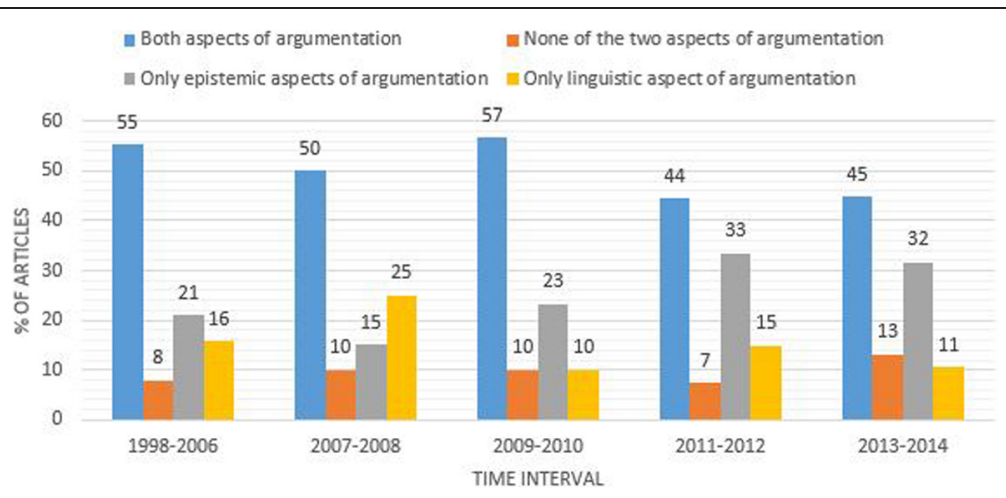

Figure 2 Distribution of journal articles with epistemic and linguistic aspects across time intervals with detailed focus in timeframes 2007-2014.

vice versa were also included in these analyses. Further analyses, in which the research articles in each journal were differentiated as those (a) articles addressing only epistemic aspects, (b) articles addressing only linguistics aspects, (c) articles addressing both aspects, and (d) articles addressing none of the two aspects, resulted in interesting findings (Figure 5).

The trend in SE and JRST looks similar in some ways; for example, at the beginning of the timeline, both journals published papers addressing either epistemic/linguistic aspect ( $27 \%$ only linguistic aspect in SE, $27 \%$ only epistemic aspect in JRST) or both of them together (55\% in SE, 55\% in JRST). On the contrary in IJSE, even in the early years of argumentation research, studies addressed diverse aspects of argumentation, including linguistic and epistemic aspects together in high percentages (56\%). Such comprehensive studies emerged in JRST beginning in 2007. For SE, the situation was reversed such that in SE, beginning from 2007, there were more argumentation studies focusing on only epistemic aspects (23\% between 2007 and 2010 and 31\% between 2011 and 2014) along with those addressing both aspects (62\% between 2007 and 2010 and 50\% between 2011 and 2014). Interestingly, in those years, linguistic aspects hardly attracted interest in SE (8\% between 2007 and
2010 and 6\% between 2011 and 2014). The 2007-2014 period made more reference to diverse aspects of argumentation.

\section{Epistemic aspects in detail}

The epistemic aspects of argumentation were examined in two groups of keywords: argumentation-specific epistemic practices such as 'claim, 'justify', 'evidence' and general or wider epistemic practices such as 'inquiry' and 'explanation'. The distribution of these keywords allowed for an analysis of trends across the journals (Figure 6). An article might have more than one keyword at the same time, and each keyword was considered separately. That is, for example, if an article had the keywords 'inquiry' and 'claim', this article was counted in both the list of articles having keyword 'inquiry' and in the list of articles having keyword 'claim'.

The analysis of the distribution of the keywords related to epistemic aspects of argumentation for each journal suggested the strongest connection between 'reason/reasoning' and 'argumentation'. The keyword 'reason', which we examined as an argumentation-specific epistemic keyword, was connected with 'argumentation' by 33.3\% of the articles. Specifically, the keyword was highly emphasized in IJSE (27\%), JRST (46.2\%) and SE (32.5\%) in

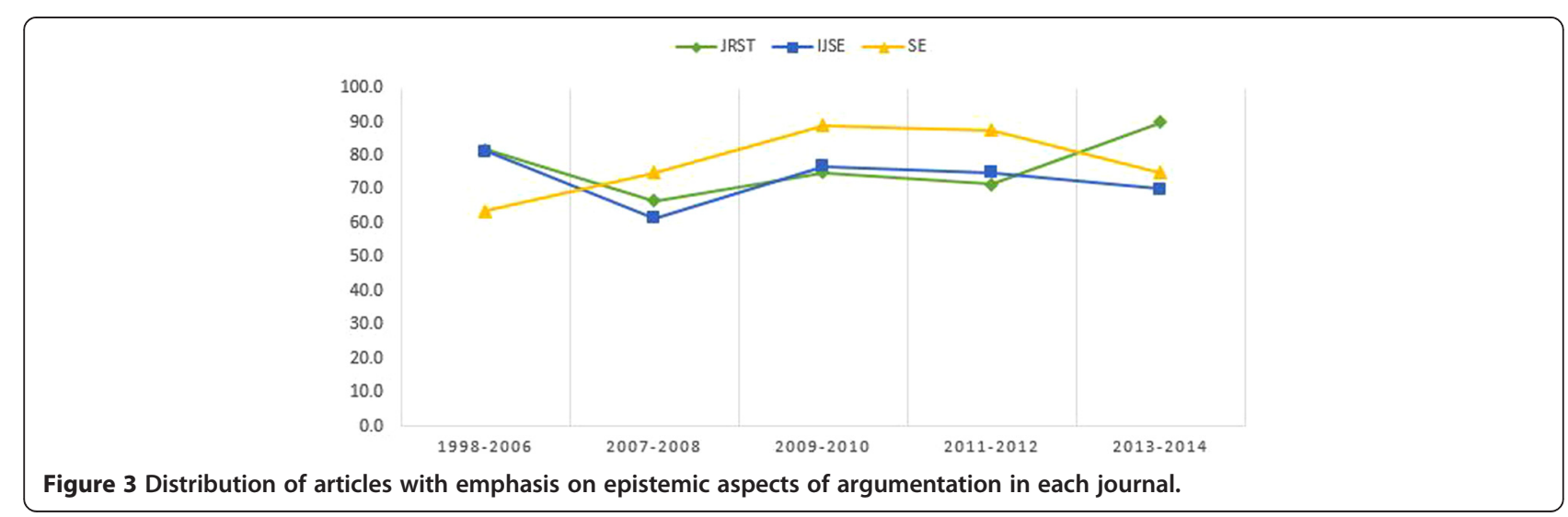




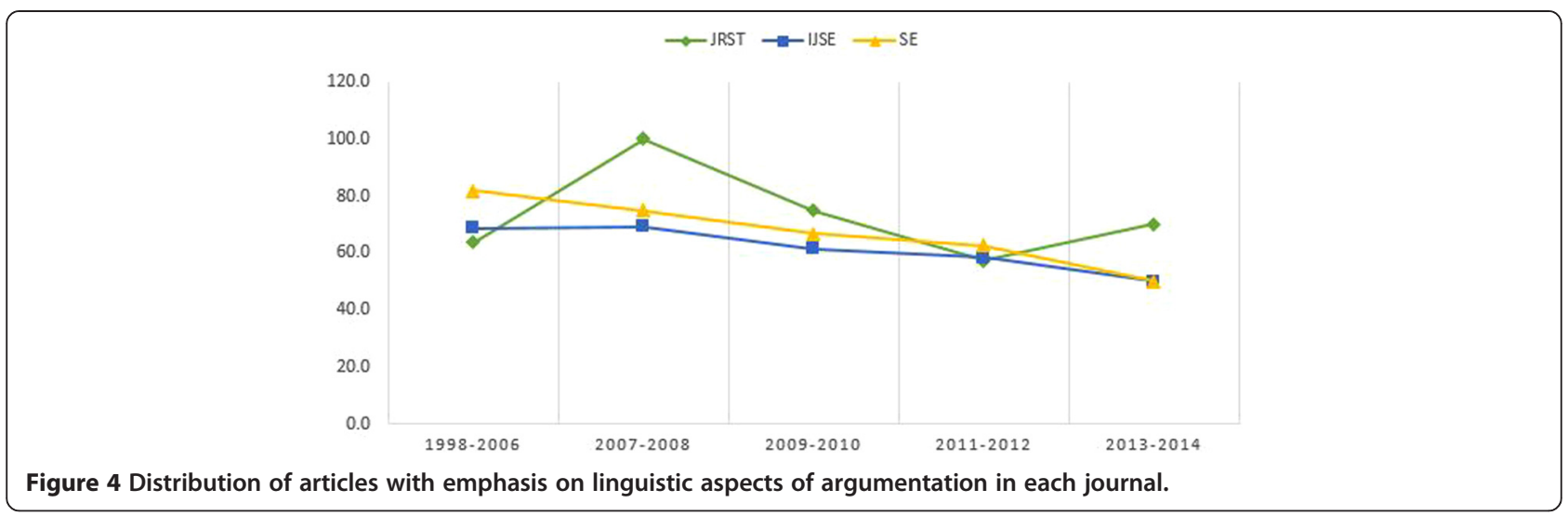

connection with argumentation. However, it is important to note that in $\mathrm{SE}$, all other keywords referring to the epistemic aspects of argumentation were emphasized at about the same percentages (between 25.0\% and 32.5\%), with an exception of 'justif-' showing a slight variation (22.5\%). The general epistemic keywords 'inquiry' and 'expla-' were related to argumentation as much as the argumentation-specific epistemic keyword 'evidence' (25.0\%). Therefore, we cannot particularly infer whether argumentation-specific keywords or general epistemic keywords had received more attention as a research focus.

The top three epistemic keywords based on the previous analysis, 'evidence,' 'reason', and 'expla-', were examined further for their distribution for each journal across years (Figure 7).

Between 1998 and 2010, the keyword 'reason' was used in relation to argumentation in high percentages. Specifically, it was emphasized in $45.5 \%$ of the articles in this time period in JRST, which is the highest compared to

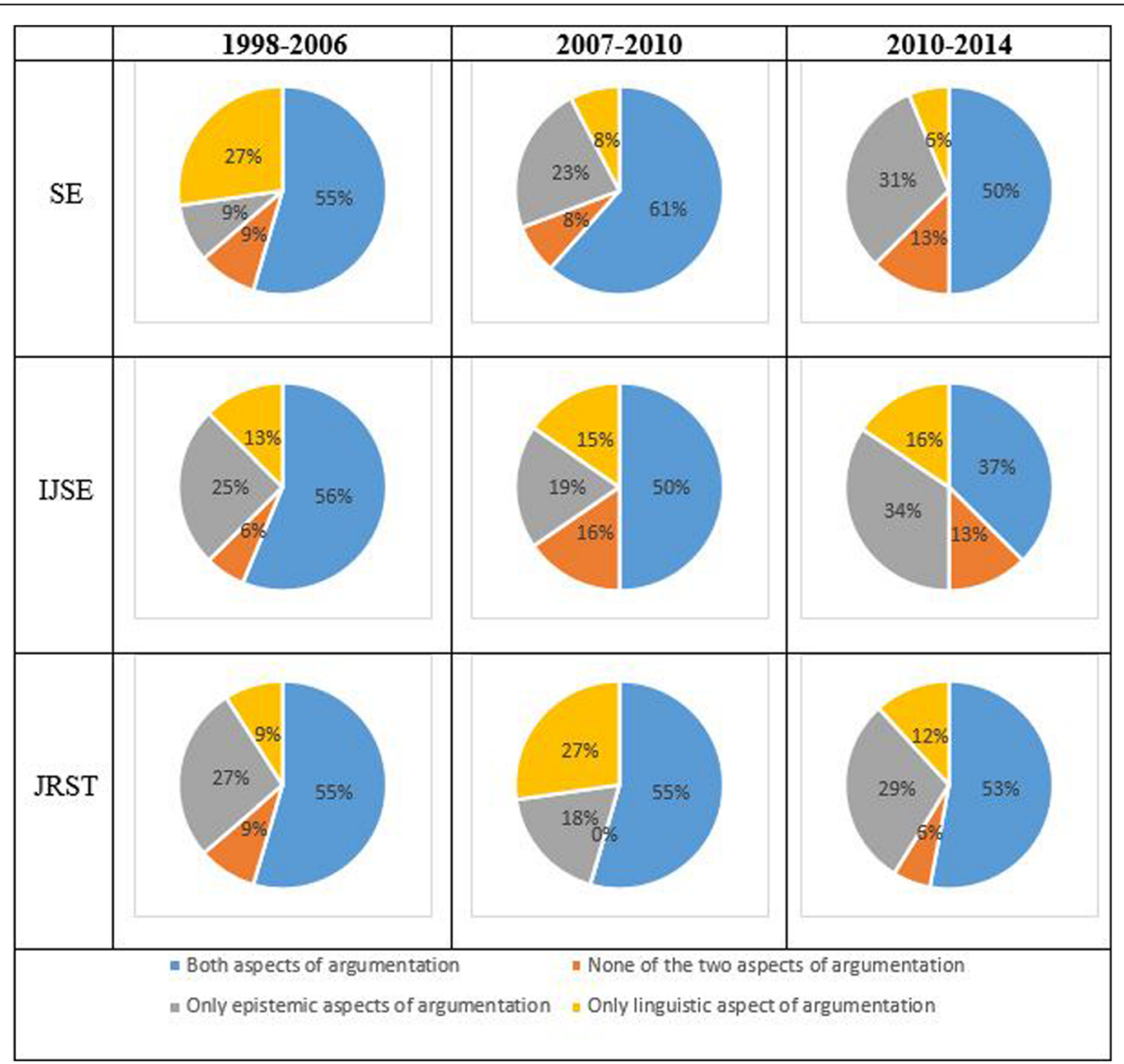

Figure 5 Distribution of papers focusing on epistemic, linguistic, both or neither aspect of argumentation across journals. 


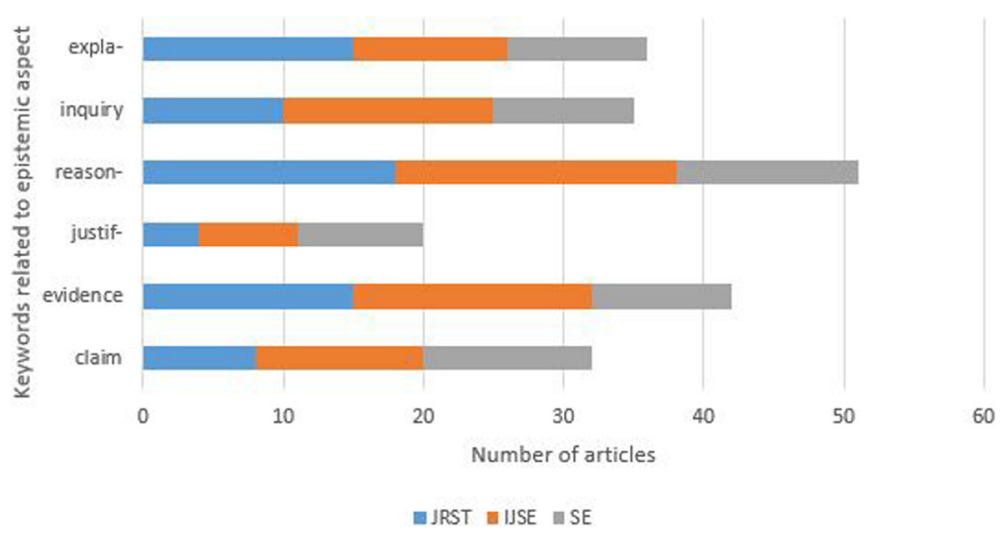

Figure 6 Keyword analysis of trends for epistemic aspects across journals.

the other keywords as well as 33.3\% in IJSE and 37.5\% in SE. The keyword 'evidence' was the most emphasized epistemic keyword in the following years in all journals (between $52.9 \%$ and $18.8 \%$ ).

\section{Linguistic aspects in detail}

The keywords illustrating linguistic aspects of argumentation were examined to identify more specific trends (Figure 8). The distribution of the keywords illustrates which linguistic aspects were emphasized mostly across journals.

In one sense, it seems as if the research made strong connections between 'discuss' and 'argumentation' (27.5\%) as well as 'discourse' and 'argumentation' (28.1\%). Specifically, in IJSE, 'discuss' was the leading linguistic keyword (32.4\% of the argumentation articles in IJSE) and 'discourse' was emphasized more than any of the linguistic keywords in JRST and in SE (35.9\% of the argumentation articles in JRST and $27.5 \%$ in SE). On the other hand, the nature of 'conversation' and 'negotiation' among the participants of argumentation did not receive so much attention (4.6\% and 5.2\%, respectively, for JRST and SE).
The top two linguistic keywords based on the previous analysis, 'discuss' and 'discourse', were examined further for their distribution for each journal across the years (Figure 9).

The trend was interesting in that although the journals showed back and forth patterns in their emphasis on each of the two keywords across the years, the total trend indicated that while in the early years, articles were establishing connections between 'discourse' and 'argumentation' (21.6\%), and recently, between 2011 and 2014, articles studied argumentation more in connection with 'discuss' (11.1\%).

\section{Conclusions}

The paper contributes to science education literature by highlighting the key conceptualizations around argumentation, a significant theme of research in recent years. The conceptualization is based on the epistemic and linguistic aspects of argumentation. By reviewing and quantifying the trends in the uptake of argumentation and related concepts, we examined the various ways in which this area of research has been covered in the literature. Our discussion presents a nuanced approach

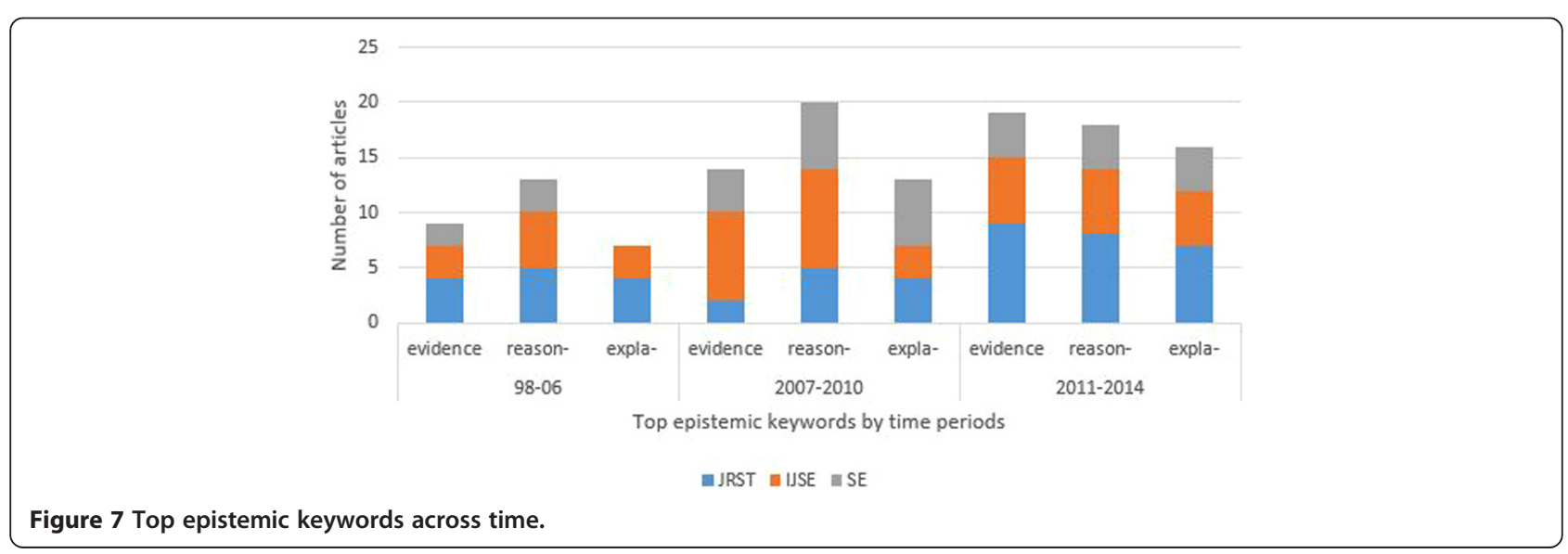




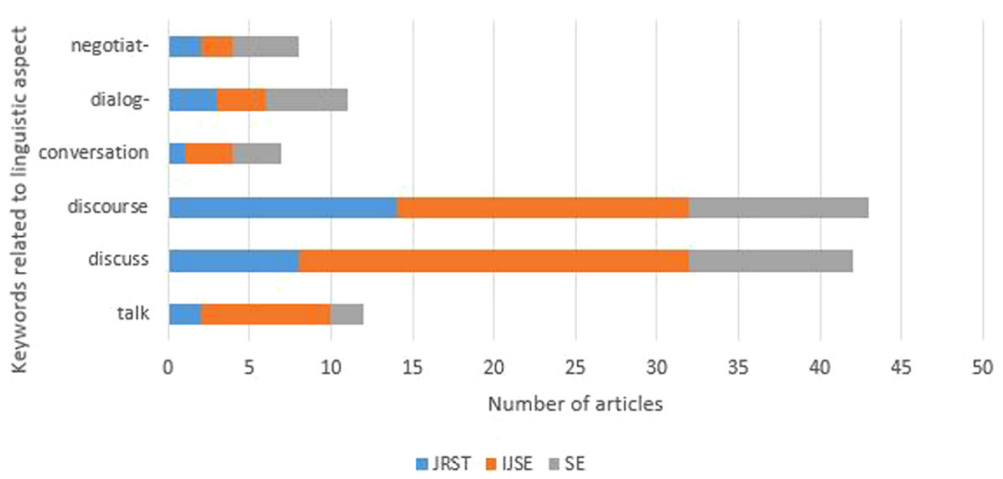

Figure 8 Keyword analysis of trends for linguistic aspects across journals.

for the finer details of how argumentation is covered across time as well as across some key journals. The study provides meta-analysis and synthesis of an important territory of research and holds the potential to contribute to the characterization of the accumulated knowledge.

One of the contributions of our analysis is the illustration that researchers studying argumentation from a linguistic perspective have been emphasizing related concepts in different ways. While the emphasis has been on 'discourse' and 'discussion' across all journals, the related concepts of 'talk', 'conversation,' 'dialogue' and 'negotiation' were observed at a lesser extent. A comparison between the epistemic aspects and linguistic aspect displays that researchers emphasized the linguistic aspect of argumentation more than the epistemic aspects. This might be the result of researchers' considering argumentation as a tool instrumental in the achievement of scientific inquiry (Erduran \& Jimenez-Aleixandre 2007) as well as a vital component of scientific discourse (Pera 1994). These findings can provide evidence-based indicators for where more emphasis needs to be placed in both research, and in particular, they can provide guidelines for journal editors in soliciting articles that target underemphasized aspects of argumentation.
The trends as investigated in this study suggest that the number of argumentation-related studies is more in IJSE compared to SE and JRST mainly because the number of issues in IJSE is 18 per year, while it is 6 per year for SE and 10 per year for JRST. However, one critical breakpoint seems to be the year 2007 for argumentation research. The number of argumentation articles were especially few between years 2005 and 2007 (Figure 1), but there is a sharp increase after the year 2007. One major explanation for this increase might be the publishing of the preliminary articles that would have probably preceded and guided the oncoming articles both in terms of philosophy and methodology. For example, TAPping into argumentation: Developments in the application of Toulmin's argument pattern for studying science discourse (Erduran et al. 2004) published in SE provided a method for analysing argumentation that was widely used by science education researchers afterwards. Patterns of informal reasoning in the context of socioscientific decision making (Sadler \& Zeidler 2005) published in JRST contributed to a theoretical knowledge base for extending the school-based research to informal learning contexts.

Another potential reason in increasing attention at argumentation studies might be the release of important

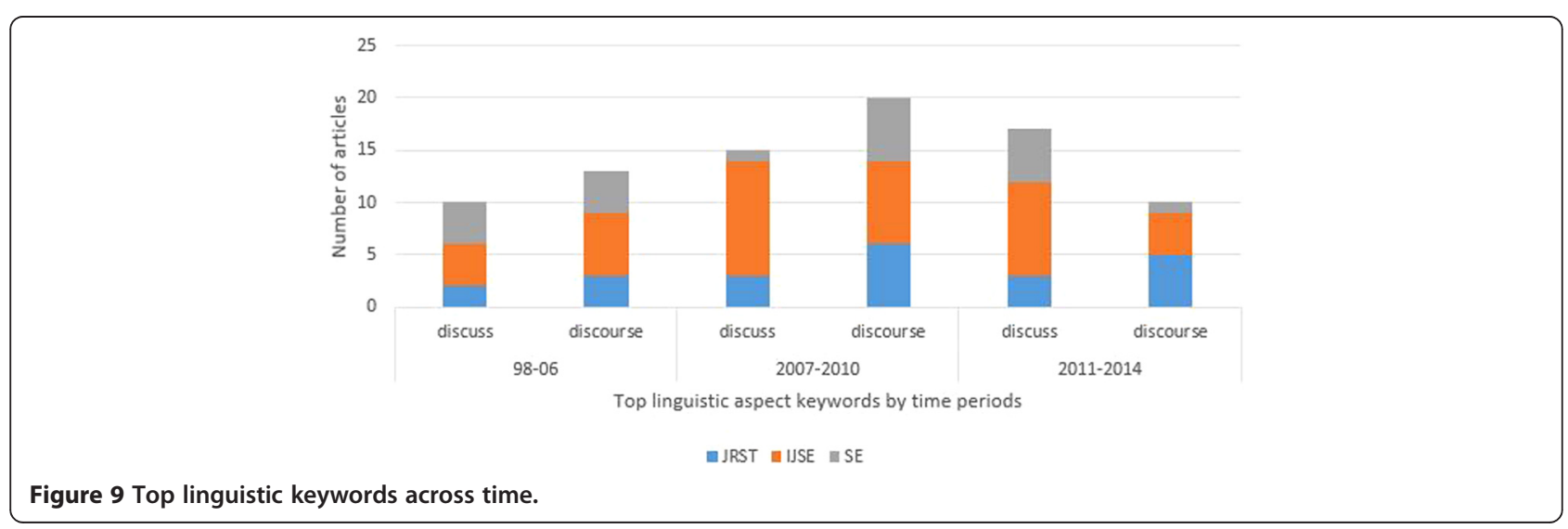


policy documents addressing argumentation in various national contexts at the beginning of 2000s leading to the necessity of research in the area. For example, in the UK, the importance of argument was set as an educational goal by means of the documents such as the Ideas and Evidence (DfES/QCA 2004) and How Science Works (Qualifications and Curriculum Authority 2007) components of the National Science Curriculum. In the new Spanish National Curriculum for secondary schooling, the relevance of the use of evidence and of argumentation is emphasized both in the general definition of basic competencies and in the description of goals in the science subjects (Ministerio de Educación y Ciencia, Spain MEC 2007). In Turkey, the national reform efforts have promoted informed citizenship where individuals make evidence-based judgements in their everyday lives including issues that relate to science (Milli Egitim Bakanligi, Turkey 2005). The examples can be extended, but the main idea is that in numerous science education policies across the world, the trends between the years 2005 and 2007 highlight the significance of argumentation with connection to scientific literacy or sciencesociety-technology goals.

In future reporting of related work, we intend to discuss detailed qualitative characterizations of the language used around 'argumentation' illustrating the range of meanings researchers have attributed to 'argumentation'. For example, while some researchers have focused on the use of Stephen Toulmin's framework of argument (e.g. Erduran et al. 2004), others have begun to incorporate Douglas Walton's scheme (e.g. Ozdem et al. 2013). However, even within the particular characterizations of argument from, say, a Toulmin perspective, there may be qualitative variations in the way that researchers have adapted his framework (e.g. Zohar \& Nemet 2002; Jimenez-Aleixandre et al. 2000). As stated at the beginning of the paper, we are also mindful of reporting on the relation of SSI and argumentation, and the trends around how these bodies of work have interacted in recent years. Hence, a detailed articulation of such variations is likely to contribute to an assessment of where and how future studies on argumentation can place a concerted effort in maximizing understanding of argumentation's utility for science teaching and learning.

Overall, the paper outlines a methodological approach on journal content analysis that is theoretically driven in terms of the epistemic and linguistic aspects of argumentation. The study provides evidence for how science educators worldwide have situated argumentation from different perspectives within the educative domain thereby generating pedagogical, curricular and instructional explanations on how argumentation in science education can be conceptualized. These results might be of use and interest to other researchers whose work does not necessarily concern argumentation but is underlined by epistemic and linguistic accounts of science teaching and learning as well as those researchers who might be interested in carrying out content analyses of journals on other topics.

\section{Abbreviations}

STEM: Science technology engineering mathematics; SSI: Socio-scientific issues; SE: Science education; IJSE: International journal of science education; JRST: Journal of research in science teaching.

\section{Competing interests}

The authors declare that they have no competing interests.

\section{Authors' contributions}

SE has made substantial contributions to the conception and design, acquisition as well as analysis and interpretation of data; has been involved in drafting the manuscript or revising it critically for important intellectual content; has given final approval of the version to be published; and agreed to be accountable for all aspects of the work in ensuring that questions related to the accuracy or integrity of any part of the work are appropriately investigated and resolved. YOY has made substantial contributions to the conception and design, acquisition as well as analysis and interpretation of data; has been involved in drafting the manuscript or revising it critically for important intellectual content; and agreed to be accountable for all aspects of the work in ensuring that questions related to the accuracy or integrity of any part of the work are appropriately investigated and resolved. JYP has made substantial contributions to the acquisition as well as analysis and interpretation of data; has given final approval of the version to be published; and agreed to be accountable for all aspects of the work in ensuring that questions related to the accuracy or integrity of any part of the work are appropriately investigated and resolved. All authors read and approved the final manuscript.

\section{Author details}

${ }^{1}$ University of Limerick, Castletroy, Co., Limerick, Ireland. ${ }^{2}$ Gaziosmanpasa University, Yeniyurt Mh, 60100 Tokat, Turkey. ${ }^{3}$ Seoul National University, 1 Gwanak-ro, Gwanak-gu, Seoul, South Korea.

Received: 4 September 2014 Accepted: 25 February 2015

Published online: 16 April 2015

\section{References}

Anderson, RD, Kahl, SR, Glass, GV, \& Smith, ML. (2006). Science education: a meta-analysis of major questions. Journal of Research in Science Teaching, 20(5), 379-385.

Bennett, J, Lubben, F, Hogarth, S, \& Campbell, B. (2005). A systematic review of the use of small-group discussions in science teaching with students aged 11-18, and their effects on students' understanding in science or attitude to science. In Research Evidence in Education Library. London: EPPICentre, Social Science Research Unit, Institute of Education.

Berland, LK, \& Reiser, B. (2009). Making sense of argumentation and explanation. Science Education, 93(1), 26-55.

Bowen, CW. (1992). A survey of types of articles published in science education literature. Journal of Experimental Education, 60(2), 13-140.

Brown, AL, \& Campione, JC. (1990). Communities of learning and thinking, or a context by any other name. In D. Kuhn (Ed.) Developmental perspectives on teaching and learning thinking skills (special issue). Contribution to. Human Development, 21, 108-126.

Buty, C, \& Plantin, C. (2008). Introduction. L'argumentation à l'épreuve de l'enseignement des sciences et vice-versa [Introduction. Argumentation put to the test of science education and vice-versa]. In C Buty \& C Plantin (Eds.), Argumenter en classe de sciences [Engaging in argumentation in science classrooms] (pp. 17-41). Lyon: Institut National de Recherche Pédagogique.

Chang, YH, Chang, CY, \& Tseng, YH. (2010). Trends of science education research: an automatic content analysis. Journal of Science Education and Technology, 19, 315-331.

Qualifications and Curriculum Authority (2007). How science works. Retrieved on March 26 from www.qca.org.uk. 
DfES/QCA. (2004). Science: the National Curriculum for England and Wales. London: HMSO.

Duschl, RA. (2008). Quality argumentation and epistemic criteria. In S Erduran \& MP Jiménez Aleixandre (Eds.), Argumentation in science education: perspectives from classroom-based research (pp. 159-175). Dordrecht: Springer.

Duschl, R, \& Grandy, R (Eds.). (2008). Teaching scientific inquiry: recommendations for research and implementation. Rotterdam: Sense Publishers.

Erduran, S. \& Jimenez-Aleixandre, MP. (2007). Research in argumentation in science education: perspectives from classroom-based research (p. 285). Dordrecht: Springer. ISBN: 978-1-4020-6669-6).

Erduran, S, \& Jimenez-Aleixandre, JM. (2012). Research on argumentation in science education in Europe. In D Jorde \& J Dillon (Eds.), Science education research and practice in Europe: retrospective and prospective (pp. 253-289). Rotterdam: Sense Publishers.

Erduran, S, Simon, S, \& Osborne, J. (2004). TAPping into argumentation: developments in the use of Toulmin's argument pattern for studying science discourse. Science Education, 88(6), 915-933.

European Union (2006). Recommendation of the European Parliament and of the Council of 18 December 2006 on key competences for lifelong learning. Official Journal of the European Union, 30-12-2006, L 394/10-L 394/18. (http://eur-lex.europa.eu/legal-content/EN/TXT/?uri=celex:32006H0962)

Foreman-Peck, L, \& Winch, C. (2010). Using educational research to inform practice: a practical guide to practitioner research in universities and colleges. London: Routledge.

Giere, R. (1988). Explaining science. A cognitive approach. Chicago: The University of Chicago Press.

Habermas, J. (1981). The theory of communicative action. Boston: Beacon Press.

Henson, KT. (2001). Writing for professional journals: paradoxes and promises. Phi Delta Kappan, 82, 765-768.

Jiménez-Aleixandre, MP, \& Federico-Agraso, M. (2009). Justification and persuasion about cloning: arguments in Hwang's paper and journalistic reported versions. Research in Science Education, 39(3), 331-347. doi:10.1007/s11165-008-9113-x.

Jimenez-Aleixandre, MP, Bugallo, A, \& Duschl, RA. (2000). "Doing the lesson" or "doing science"; argument in high school genetics. Science Education, 84(6), 757-792

Kelly, GJ, \& Chen, C. (1999). The sound of music: constructing science as sociocultural practices through oral and written discourse. Journal of Research in Science Teaching, 36(8), 883-915.

Kelly, GJ, \& Takao, A. (2002). Epistemic levels in argument: an analysis of university oceanography students' use of evidence in writing. Science Education, 86(3), 314-342

Kitcher, P. (1988). The child as parent of the scientist. Mind and Language, 3(3), 215-228

Kuhn, D, \& Crowell, A. (2011). Dialogic argumentation as a vehicle for developing young adolescents' thinking. Psychological Science, 22(4), 545-552. doi:10.1177/0956797611402512.

Lee, M-H, Wu, Y, Tien, T, \& Chin-Chung, A. (2009). Research trends in science education from 2003 to 2007: a content analysis of publications in selected journals. International Journal of Science Education, 31(15), 1999-2020.

Lemke, J. (1990). Talking science. Language, learning and values. Norwood, NJ: Ablex.

Lin, TC, Lin, TJ, \& Tsai, CC. (2014). Research Trends in Science Education from 2008 to 2012: a systematic content analysis of publications in selected journals. International Journal of Science Education, 36(8), 1346-1372.

Mason, L. (1996). An analysis of children's construction of new knowledge through their use of reasoning and arguing in classroom discussions. International Journal of Qualitative Studies in Education, 9(4), 411-433.

Milli Egitim Bakanligi, Turkey. (2005). Ilkögretim fen ve teknoloji dersi ögretim programi (6, 7 ve 8. siniflar). Ankara, Turkey: Milli Egitim Bakanligi.

Ministerio de Educación y Ciencia, Spain (MEC). (2007). Real decreto 1631/2006 enseñanzas mínimas educación secundaria obligatoria. Boletín Oficial de Estado, 5, 677-773.

Mortimer, EF, \& Scott, PH. (2003). Meaning making in secondary science classrooms. Maidenhead: Open University Press.

National Research Council. (2012). A framework for K-12 science education. Washington, DC: National Academies Press.

Organisation for Economic Cooperation and Development. (2006). PISA 2006. Assessing scientific, reading and mathematical literacy: a framework for PISA 2006. Paris: OECD.

Ozdem, Y, Cakiroglu, J, Ertepinar, H, \& Erduran, S. (2013). The nature of pre-service science teachers' argumentation in inquiry-oriented laboratory context. International Journal of Science Education, 35(15), 2559-2586.
Pera, M. (1994). The discourses of science. Chicago: University of Chicago Press. Sadler, TD, \& Zeidler, DL. (2005). Patterns of informal reasoning in the context of socioscientific decision making. Journal of Research in Science Teaching, 42(1), 112-138.

Sandoval, WA, \& Millwood, KA. (2005). The quality of students' use of evidence in written scientific explanations. Cognition and Instruction, 23(1), 23-55.

Siegel, H. (1989). The rationality of science, critical thinking and science education. Synthese, 80, 9-41.

Slavin, RE, Lake, C, Chambers, B, Heung, A, \& Davis, S. (2009). Effective reading programs for the elementary grades: a best-evidence synthesis. Review of Educational Research, 79(4), 1391-1466.

Toulmin, S. (1958). The uses of argument. Cambridge, England: Cambridge University Press.

Zohar, A, \& Nemet, F. (2002). Fostering students' knowledge and argumentation skills through dilemmas in human genetics. Journal of Research in Science Teaching, 39(1), 35-62

\section{Submit your manuscript to a SpringerOpen ${ }^{\odot}$ journal and benefit from:}

- Convenient online submission

Rigorous peer review

- Immediate publication on acceptance

- Open access: articles freely available online

- High visibility within the field

- Retaining the copyright to your article

Submit your next manuscript at $>$ springeropen.com 